\title{
NEW GENUS AND SPECIES OF THE TRIBE PARAHIRACIINI (HEMIPTERA, FULGOROIDEA, ISSIDAE) FROM THE PHILIPPINES AND VIETNAM
}

\author{
Vladimir M. GNEZdilov \\ Zoological Institute, Russian Academy of Sciences \\ Universitetskaya nab. 1, St. Petersburg 199034, Russia \\ E-mail:vmgnezdilov@mail.ru,vgnezdilov@zin.ru
}

\begin{abstract}
Nisoprincessa gen. $\mathrm{n}$. is described for Nisoprincessa palawana sp. $\mathrm{n}$. from Palawan Island of the Philippines. This represents the first record of the tribe Parahiraciini in the Philippines. Nisoprincessa palawana sp. $\mathrm{n}$. is treated as two subspecies according to the length of metopial proboscis - N. palawana palawana ssp. n. and N. palawana bacuita ssp. n. Furthermore, Brevicopius gorochovi sp. $\mathrm{n}$. is described from Vietnam which is the first record of the genus Brevicopius Meng, Qin et Wang, 2015 in the country.
\end{abstract}

Key words. Parahiraciini, Brevicopius, Thabenula, morphology, taxonomy, Palawan, Central Vietnam.

\section{INTRODUCTION}

Currently, the tribe Parahiraciini comprises 18 genera with 70 species in the modern fauna, and one monotypic genus is known from the Baltic amber (GNezdilov 2013, Wang et al. 2015, Gnezdilov \& Bourgoin 2016, Gnezdilov \& HAyAshi 2016, Bourgoin 2017). The tribe can be treated as an endemic taxon in the Oriental Region with only a few species also recorded from the Eastern Palaearctic and Oceanic regions (Gnezdilov 2013, ZhANG \& Chen 2013).

The members of the tribe are characterised by body more or less flattened dorso-ventrally, metope often projecting, usually with a proboscis, beetle-shaped (convex, coriaceous, not exceeding the length of abdomen) fore wings, usually with keel-shaped veins, caudo-dorsal angle of clavus of fore wings usually in shape of distinct triangular lobe - cuspidal apex of clavus (GNezDILov 2015, fig. 8), hind wings very often bilobate (two almost symmetric lobes, with anal lobe of vannus reduced), except Scantinius Stål, 1866 and the new genus described below which have trilobate hind wings (with anal lobe of vannus developed), long fore legs, and style with convex margin under the capitulum.

Herewith, a new genus and species from the Philippines and a new species of the genus Brevicopius Meng, Qin et Wang, 2015 from Central Vietnam are described. Nisoprincessa palawana gen. et sp. n. represents the first record of the tribe Parahiraciini in the Philippines and Brevicopius gorochovi sp. n. is 
the first record of the genus from the mainland together with the type species of the genus; Brevicopius jianfenglingensis (Chen, Zhang et Chang, 2014) which was known before only from Hainan Island (Chen et al. 2014, Meng et al. 2015) and recorded herein also from Central Vietnam.

\section{MATERIAL AND METHODS}

The species discussed below including the type specimens of the species described are deposited in the following collections: IRSNB - Institut Royal des Sciences Naturelles de Belgique, Brussels, Belgique; MMBC - Moravian Museum, Brno, Czech Republic; USNM - Smithsonian Institution, National Museum of Natural History, Washington, D.C., USA; ZIN - Zoological Institute of the Russian Academy of Sciences, Saint Petersburg, Russia.

Morphological terminology follows GNEzDiLov et al. (2014).

The drawings were made using Leica MZ95 light microscope. The photos of Brevicopius spp. were taken using Leica MZ8 with JVC video camera KY F7OB in the National Museum of Wales (Cardiff, UK). The photos of Nisoprincessa palawana sp. n. were taken in the Museum für Naturkunde (Berlin, Germany) using a Leica Z16 APOA microscope with a Leica DFC490 video camera. Images are produced using the software Leica Application Suite ver. 3.7, Auto-Montage Essentials, Synoptics Automontage, and Adobe Photoshop.

\section{TAXONOMY}

Issidae Spinola, 1839

Issinae Spinola, 1839

Parahiraciini Cheng et Yang, 1991

\section{Nisoprincessa gen. $n$.}

Type species: Nisoprincessa palawana sp. n.

Diagnosis. Metope protruding in shape of proboscis, with distinct median and sublateral carinae (Figs 1-3, 9). Fore wings without transverse veins and with pustules between longitudinal veins. Postcubitus of fore wing not reaching first anal vein on clavus (Figs 11,12). Hind wings trilobate, with two deep marginal clefts (Fig. 13). CuA and CuP of hind wings fused medially and separated apically. Fore and middle femora foliately flattened (Figs 4, 5). Fore femora are longest and hind femora are shortest (Fig. 6).

Description. Coryphe and metope joint at obtuse angle (in lateral view) (Figs 3, 9), metope well visible from above (Fig. 2). Border between coryphe and metope smooth, weakly recognizable. Metope elongate, with distinct median and sublateral carinae which not reaching its upper margin (Fig. 34); lateral margins convex medially. Metope protruding in shape of proboscis (in lateral view), with 12 pustules between lateral and sublateral carinae on each side. Coryphe elongate, 1.4 times as long laterally as wide at midline, with weak median carina; anterior margin convex; posterior margin obtusely angulate. Ocelli 
present. Postclypeus large, without carinae. Pedicell elongately cylindrical. Second and third segments of rostrum nearly equal in length. Third segment of rostrum slightly narrowing apically, reaching hind coxae. Pronotum nearly as long as coryphe at midline, with weak median carina; anterior margin convex, with 16 pustules along its margin; posterior margin nearly straight, with 5 pustules along its margin (Fig. 10). Paradiscal fields narrow,

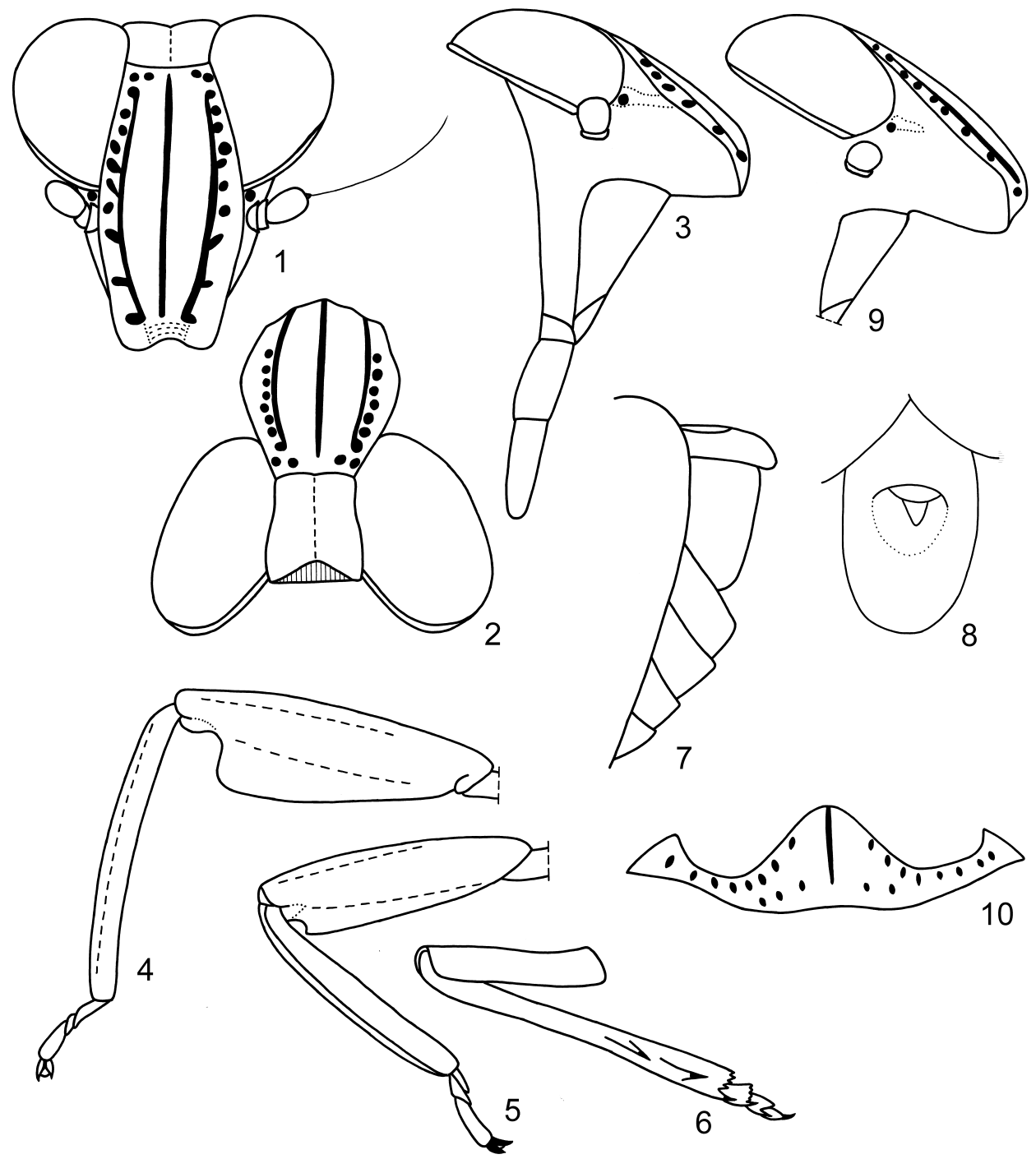

Figs 1-10. Nisoprincessa palawana gen. et sp. n. $1-8=N$. p. palawana ssp. n., holotype, $1=$ head, frontal view; 2 = head, dorsal view; 3 = head, lateral view; $4=$ left fore leg; $5=$ left middle leg; $6=$ left hind leg; $7=$ female genital block, lateral view; $8=$ female anal tube, dorsal view; $9-10=$ N. p. bacuita ssp. n., holotype: $9=$ head, lateral view; $10=$ pronotum, dorsal view 
distinct. Paranotal lobes widely triangular. Mesonotum longer than pronotum, with weak median and lateral carinae. Fore wings reaching apex of anal tube, elongately oval, convex (Figs 11, 33, 35). Costal margin angularly convex basally. Basal cell narrow. R 2 - furcating closely to basal cell, M 2 - furcating in basal part of wing, CuA 2 (same specimen has on one wing $\mathrm{CuA} 2$ and on another - CuA 3) - furcating before apex of clavus (Fig. 11). Transverse veins absent, but pustules presented between longitudinal veins (Fig. 12). Clavus 0.5 times as long as whole wing. Pcu not reaching $A_{1}$ (Fig. 13). Hind wings as long as fore wings, trilobate (with anal lobe of vannus rather narrow, but distinct), with two deep marginal clefts - between $\mathrm{CuA}$ and $\mathrm{CuP}$ and between branches of $\mathrm{A}_{1}$. Basal cell large. $\mathrm{R} 1$ M 1 CuA 1 CuP 1 Pcu $1 \mathrm{~A}_{1} 2 \mathrm{~A}_{2} 1$; CuA and CuP fused medially and separated apically; anterior branch of $\mathrm{A}_{1}$ fused medially with $\mathrm{Pcu}$; marginal vein thick on terminal parts of the lobes (Fig. 13). Fore and middle femora flattened and foliate (mostly fore femora) (Figs $4,5)$. Fore and middle tibiae flattened. Hind femora and tibiae not flattened nor foliated (Fig. 6). Fore femora and tibiae are longest; middle tibiae nearly equal in length or slightly shorter than hind tibiae; hind femora are shortest. Hind tibia with 2 lateral spines in its

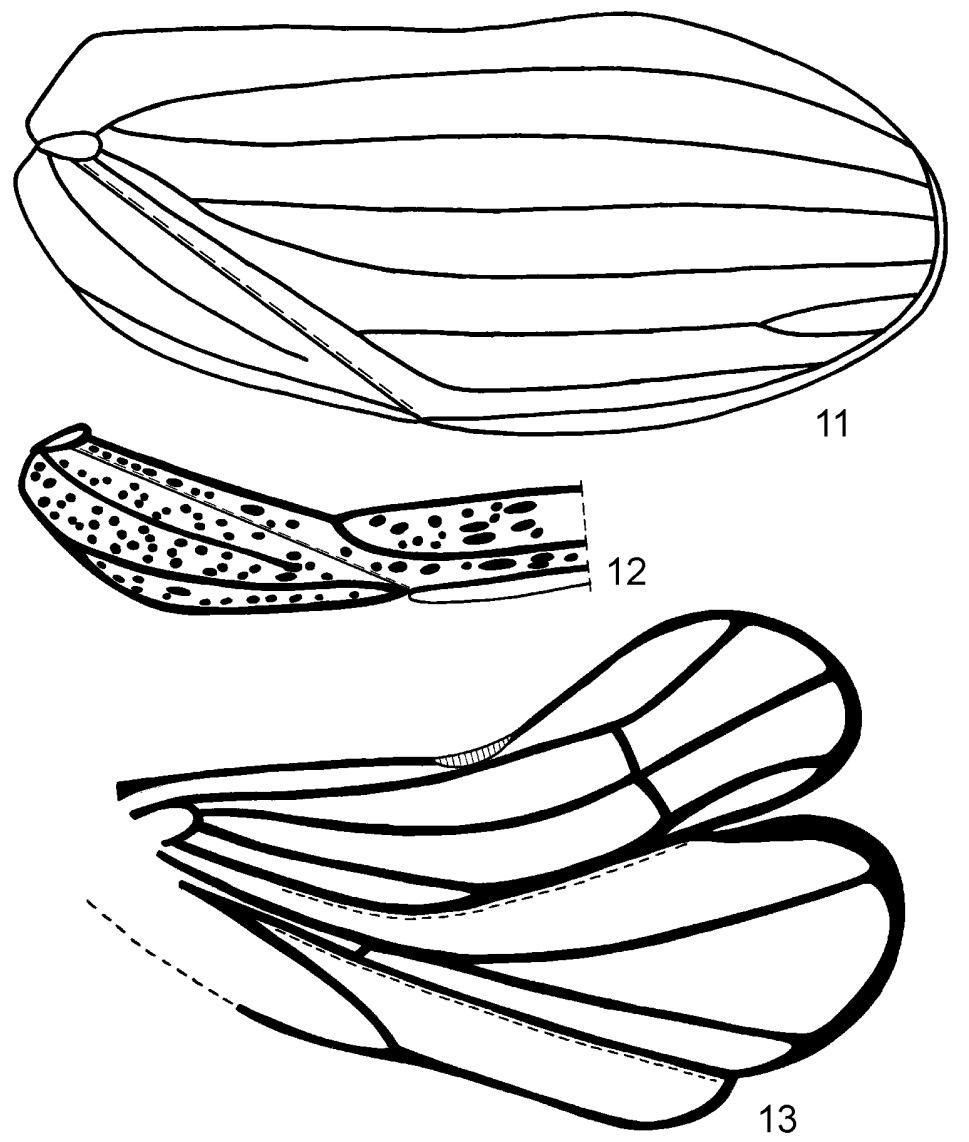

Figs 11-13. Nisoprincessa palawana gen. et sp. n. 11-12 = N. palawana palawana ssp. n., holotype: 11 = fore wing; 12 = clavus; $13=N$. palawana bacuita ssp. $n$., holotype, hind wing 
distal half and 6 apical spines. First and second tarsomeres of fore and middle legs short, nearly equal in length, third tarsomere as long as first and second together. First metatarsomere longer than second one; second and third metatarsomeres nearly equal in length. First metatarsomere with 2 latero-apical and 7 intermediate spines in regular row (without gaps). Second metatarsomere with only 2 latero-apical spines. Hind margin of arolium of pretarsus convex, not reaching apices of claws (in dorsal view); dorso-lateral plates wide.

Hind margin of female sternite VII widely concave. Gonoplacs convex, without carinae (Fig. 7). Anal tube 1.3 times as long as wide, anterior margin widely rounded; paraproct short (Fig. 8).

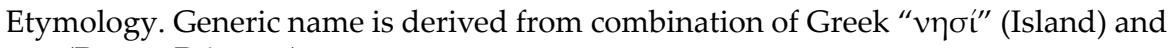
Princessa (Puerto Princesa).

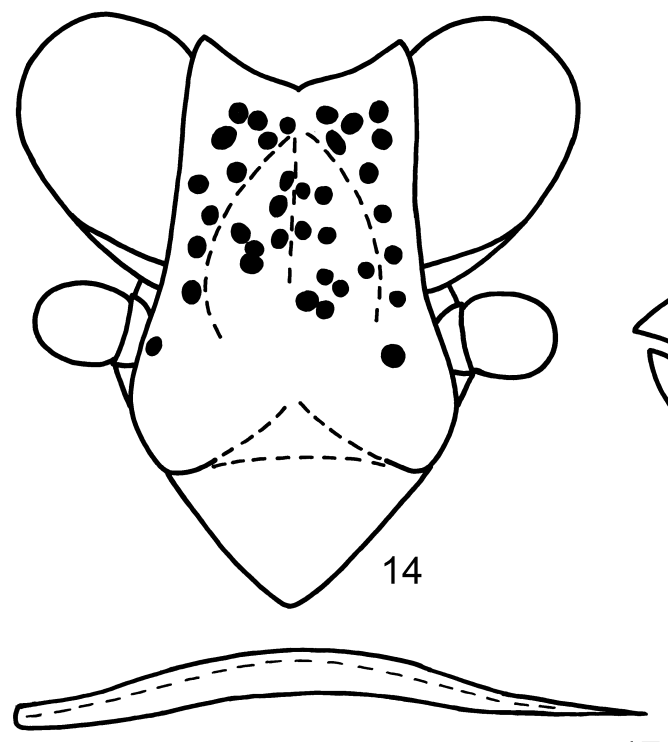

17
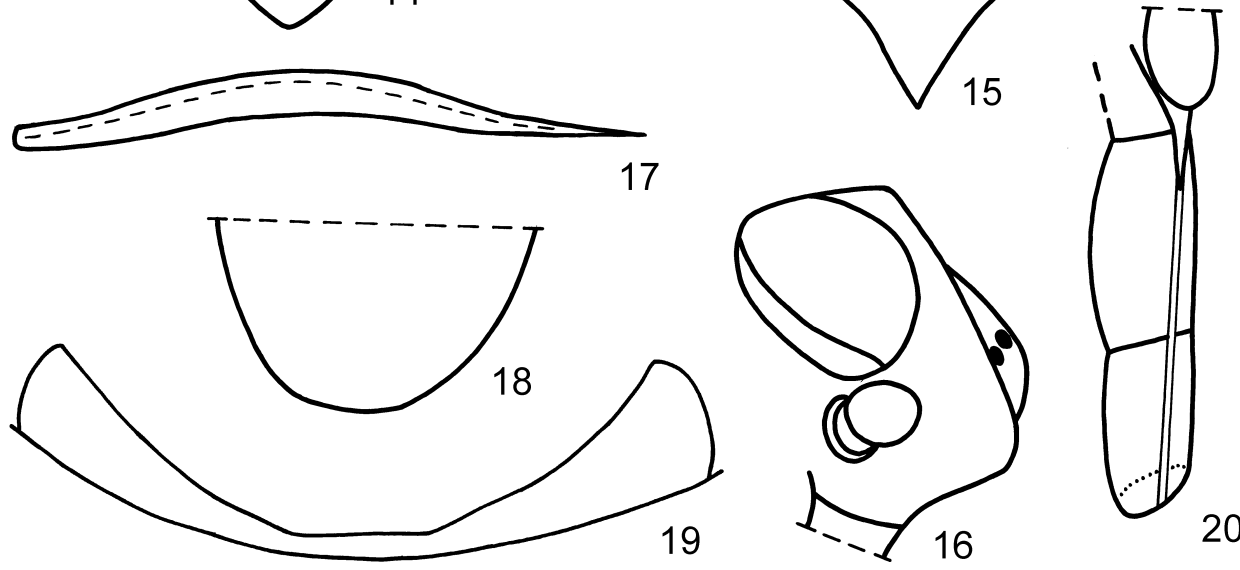

Figs 14-20. Brevicopius jianfenglingensis Chen, Zhang et Chang. 14-19= female: $14=$ head, frontal view, 15 = head, pro-, and mesonotum, dorsal view, 16 = head, lateral view; $17=$ hypocostal plate of fore wing, 18 = apical part of female anal tube, dorsal view, $19=$ hind margin of female sternite VII, ventral view; $20=$ male, rostrum, lateral view 


\section{Nisoprincessa palawana sp. $\mathrm{n}$.}

Description. Morphology as mentioned for the genus.

Colouration. General coloration dark brown (Figs 33-35). Metope with light carinae and pustules. Genae with light stripes running across the ocelli (dotted line on figs 3 and 9). Postclypeus with brown lateral parts and with light brown band basally. Anteclypeus dark brown to black except light brown yellowish basal part. Rostrum light brown with black apex. Pro- and mesonotum dark brown yellowish, with yellowish carinae and pustules. Fore wings with greenish veins and light pustules. Hind wings semitransparent, with dark brown veins. Hind epimerae and episternae with large black spots. Notum between trochanters light yellow. Trochanters of fore and middle legs light yellow. Fore and middle femora with light spots and dots. Fore and middle tibiae with light outer margins. Hind femora dark brown to black. Hind tibiae dark brown basally, light brown yellowish medially and dark brown apically. Tarsi and claws with pretarsus dark brown. Apices of leg spines black. Abdominal sternites VI-VII dark brown laterally and almost black medially. Gonoplacs sometimes mainly light brown yellowish. Margins of gonoplacs and anal tube black.

Note. The species is presented by two females which are clearly differ each from other by the length of metopial proboscis and the shape of light stripes of genae (Figs 3, 9). The type localities of these specimens are situated in Puerto Princesa and in Bacuit Bay which is $238 \mathrm{~km}$ NE of Puerto Princesa, thus it is rather possible to expect even different species in these localities, but at the moment I have no males and prefer to describe subspecies for these females until males will be discovered and examined.

\section{Key to subspecies of Nisoprincessa palawana}

1 Metopial proboscis as long as postclypeus (in lateral view) (Fig. 9). Light stripe of gena not reaching lateral margin of metope (dotted line on fig. 9). Total length $-6.0 \mathrm{~mm}$

N. palawana bacuita ssp. $n$.

- Metopial proboscis 0.6 times as long as postclypeus (in lateral view) (Fig. 3). Light stripe of gena reaching lateral margin of metope (dotted line on fig. 3). Total length $-5.5 \mathrm{~mm}$

N. palawana palawana ssp. $n$.

\section{Nisoprincessa palawana palawana ssp. $\mathrm{n}$.}

$$
\text { (Figs 1-8, 11, 12, 33, 34) }
$$

Type material. Holotype, ㅇ, "P. Princesa / Palawan / Baker", “Collectio / Dr. L. Melichar / Moravské museum Brno", "Arhopoda timida [? Horv.]”, "Nomen invalidum (Manuscript name) / P. Lauterer det. 1987" (MMBC). 


\section{Nisoprincessa palawana bacuita ssp. $\mathrm{n}$.}

(Figs 9, 10, 13, 35)

Type material. Holotype, ㅇ, “N. Palawan / Bacuit / Dezemb. 1913 / leg. G. Roet'cher”, "Bardunia nasuta Mel. [hand written in ink] / det. Melichar [printed]", "Collectio / Dr. L. Melichar / Moravské museum Brno" (MMBC).

\section{Brevicopius Meng, Qin et Wang, 2015}

Type species: Fortunia jianfenglingensis Chen, Zhang et Chang, 2014

\section{Brevicopius gorochovi sp. n.}

$$
\text { (Figs 21-32, 39-44) }
$$

Type material. + Holotype, Vietnam, Gia Lai Province, Buon Luoi, 22.III.1995, A.V. Gorochov leg. (ZIN).

Description. Metope elongate, convex above postclypeus - this lower part of metope joint to its upper flat part at right angle (in lateral view) (Figs 22, 24, 42, 43). Metope with sublateral carinae joint below its upper margin in shape of hourse-shoe and with pustules between sublateral carinae and upper and lateral margins. Inside of hourse-shoe at midline there is large triangular pustule (Fig. 22). Upper margin of metope deeply trapezoidally concave (Figs 22, 43). Metopoclypeal suture distinct, convex. Postclypeus large, smooth. Ocelli absent. Pedicell elongately cylindrical. Rostrum reaching hind coxae, its second and third segment nearly equal in length; third segment not narrowing apically (cylindrical) (Fig. 21). Metope and anterior part of coryphe joint at right angle (in lateral view) (Figs 24, 42). Coryphe transverse, concave along midline (Figs 23, 40). Anterior and posterior parts of coryphe nearly equal in length along midline and joint at obtuse angle; posterior part is more convex. Pronotum and mesonotum nearly equal in length along midline. Pronotum with pustules along its anterior margin and besides of midline. Paradiscal fields wide, with pustules except smooth areas behind the eyes. Paranotal lobes widely triangular. Mesonotum concave medially. Tegulae small. Fore wings elongate, with kell-shaped longitudinal veins, with wide hypocostal plate (Figs 25, 26, 39, 41). Clavus slightly longer than $1 / 3$ of wing length. Basal cell narrow, weakly recognisable. R 2 - furcating near to basal cell, $\mathrm{M}$ 2 , CuA 3 - both furcating at the same level before apex of clavus. Postclaval parts of fore wings crossing (in dorsal view). Hind wings as long as fore wings. Fore femora are longest, hind femora are shortest (Figs 29, 30). Fore and middle femora and tibiae flattened (Figs 29, 31). Hind tibiae are longest. Hind tibia with 2 lateral spines in distal half and with 7 apical spines. First and second tarsomeres of fore and middle legs nearly equal in length, third tarsomere 2-2.5 times longer. First and second metatarsomeres nearly equal in length, with long hair-shaped setae on ventral surface. First metatarsomere with 2 latero-apical and 6 intermediate spines. Second metatarsomere with only 2 latero-apical spines. Arolium of pretarsus not exciding apices of claws, with convex hind margin (in dorsal view) (Fig. 32). Hind margin of female sternite VII with two concavities (Fig. 28). Anal tube wide, with median concavity apically (Fig. 27). Gonoplacs convex, without carinae (Fig. 44). 
Colouration. Head, pro- and mesonotum light brown yellowish (Figs 39, 40). Metope dark brown to black, with black upper angles; sublateral carinae, median triangular, and pustules light yellow (Fig. 43). Genae light brown yellowish, with red dots and with black
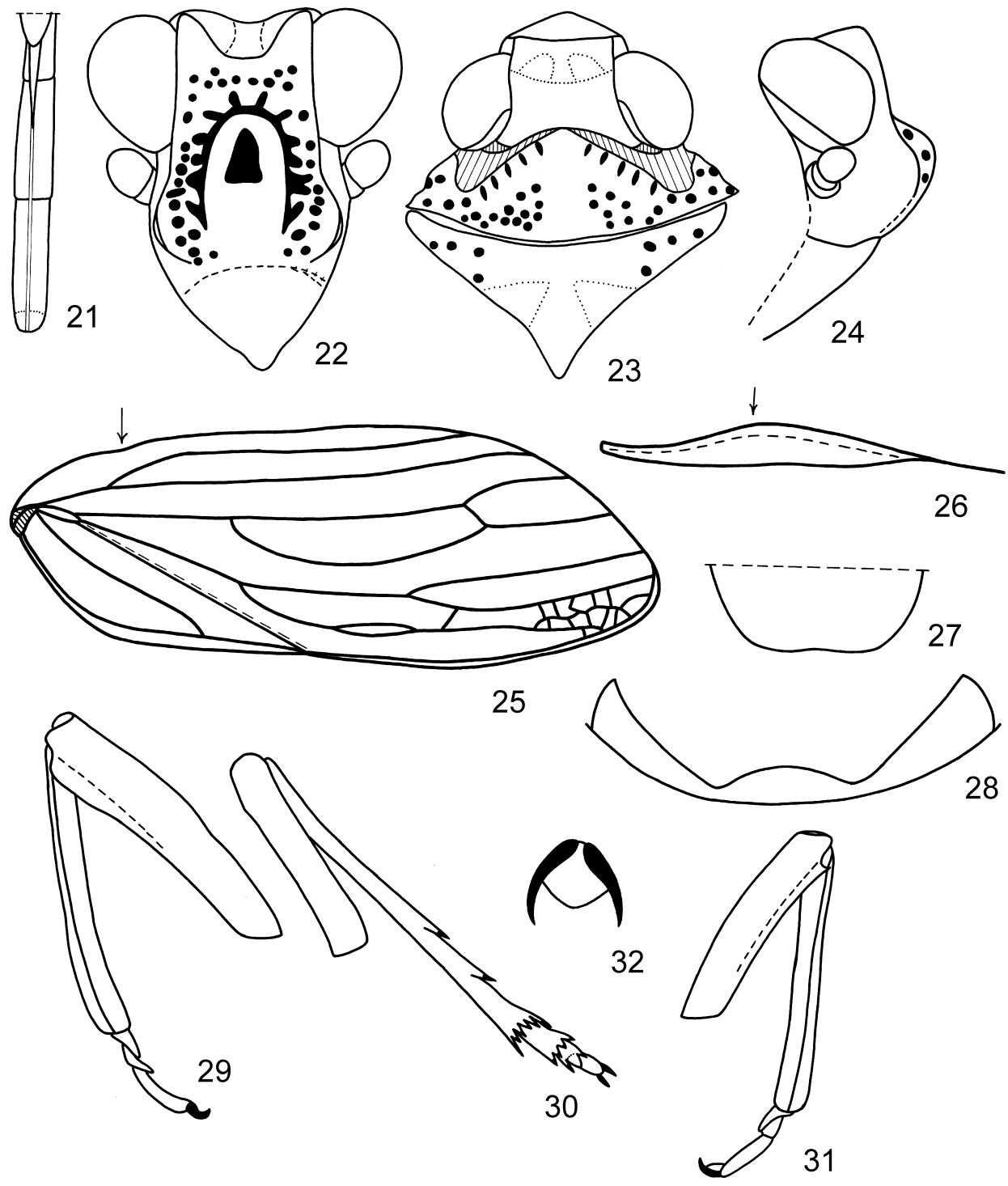

Figs 21-32. Brevicopius gorochovi sp. n., holotype. $21=$ rostrum, $22=$ head, frontal view, 23 = head, pro-, and mesonotum, dorsal view, 24 = head, lateral view, 25 = fore wing, $26=$ hypocostal plate of fore wing, $27=$ apical part of female anal tube, dorsal view, $28=$ hind margin of female sternite VII, ventral view, 29 = right fore leg, 30 = left middle leg, 31 = left hind leg, 32 = pretarsus of left fore leg 
stripe along eye margin (Fig. 42). Scapus and pedicel light green yellowish. Clypeus dark brown to black. Rostrum green yellowish. Pronotum with black posterior margin. Mesonotum with dark brown upper angles. Fore wings with brown yellowish $\mathrm{R}$ and transverse veins and with black cells basally and behind the hypocostal plate (Figs 39, 41). M and CuA green yellowish with dark brown and black cells between them, transverse veins reddish. Clavus with dark brown to black cells and with reddish transverse veins, Pcu greenish, $\mathrm{A}_{1}$ brown. Hind wings dark brown. Fore coxae and femora dark brown to black, with light


Figs 33-38. Parahiraciini. 33-34 = Nisoprincessa palawana palawana ssp. n., holotype: $33=$ dorsal view, $34=$ frontal view. $35=N$. palawana bacuita ssp. $n$., holotype, lateral view. 36-38 = Brevicopius jianfenglingensis Chen, Zhang et Chang, male: 36-37 = dorsal view, $38=$ frontal view 
spots outside apically and light yellow, with brown spots inside. Fore femora and tarsi dark brown. Fore tibiae with two large light brown yellowish patches at its middle and proximally (Fig. 41). Middle trochanters dark brown outside and light yellow inside. Middle coxae light yellow. Middle femora light yellow, with brown spots and dots and dark brown outside basally and apically. Middle tarsi dark brown. Hind coxae dark brown to black. Hind trochanters dark brown. Hind femora dark brown to black outside and brown yellowish inside. Hind tibiae light yellow greenish, with brown spots. Hind tarsi light yellow greenish. Third metatarsomere brown apically, claws dark brown. Apices of leg spines black. Third abdominal sternite brown yellowish, with black lateral parts. Abdominal sternite VI black medially. Abdominal sternites V-VI brown to dark brown and black medially. Abdominal sternite VII light brown, with black median lobe (Fig. 44). Abdominal laterotergites VI-VII black. Gonocoxa VIII dark brown to black, with light yellow hind margin. Gonoplacs dark brown, with two orange patches medially. Anal tube yellow greenish.

Total length. $11 \mathrm{~mm}$.

Etymology. The species is named after the well-known Russian orthopterologist Dr. Andrey Gorochov.

\section{Brevicopius jianfenglingensis (Chen, Zhang et Chang, 2014)}

(Figs 14-20)

Fortunia jianfenglingensis Chen, Zhang et Chang, 2014: 94 (sp. n.).

Brevicopius jianfenglingensis Meng, Qin et Wang, 2015: 585 (comb. n.).

Material examined. Vietnam: 1 đ̊, "Annam Province / Haut Donai / Col de Blao”, “Alt. 900 M. / 11.5.1933”, “M. Poilane / Coll.” (USNM); 1 +, Dak Lak Province, Chu Yang Sin Nat. Park, 2-10.VII.2007, P. Grootaert leg. (IRSNB).

\section{Key to species of Brevicopius}

1 Upper margin of metope trapezoidally concave (Figs 22, 43). Metope angularly convex above the clypeus (Figs 24,42). Coryphe devided into anterior and posterior parts joint at obtuse angle (Figs 23, 40). Third segment of rostrum nearly as long as second one (Fig. 21). Fore wings with wide hypocostal plate (Fig. 26) and green yellowish M and CuA (Fig. 39). Hind margin of female sternite VII with two concavities (Fig. 28). Female anal tube widely rounded apically, with median concavity (Fig. 27). Total length $-11 \mathrm{~mm}$. Central Vietnam B. gorochovi sp. $\mathrm{n}$.

- $\quad$ Upper margin of metope obtusely angulately concave (Figs 14, 38). Metope slightly convex above the clypeus (Fig. 16). Coryphe not devided into two parts (Figs 15,37). Third segment of rostrum shorter than second one (Fig. 20). Fore wings with narrow hypocostal plate (Fig. 17) and 
light brown $\mathrm{M}$ and $\mathrm{CuA}$ (Fig. 36). Hind margin of female sternite VII widely concave (Fig. 19). Female anal tube narrowing apically, without concavity (Fig. 18). Total length $-9 \mathrm{~mm}$. China (Hainan I.), Central Vietnam B. jianfenglingensis (Chen, Zhang et Chang, 2014)

\section{DISCUSSION}

According to the shape of proboscis and foliately flattened fore and middle femora Nisoprincessa gen. n. is conceivable, even likely closely related to the genera Narinosus Gnezdilov et Wilson, 2005 and Folifemurum Che, Zhang
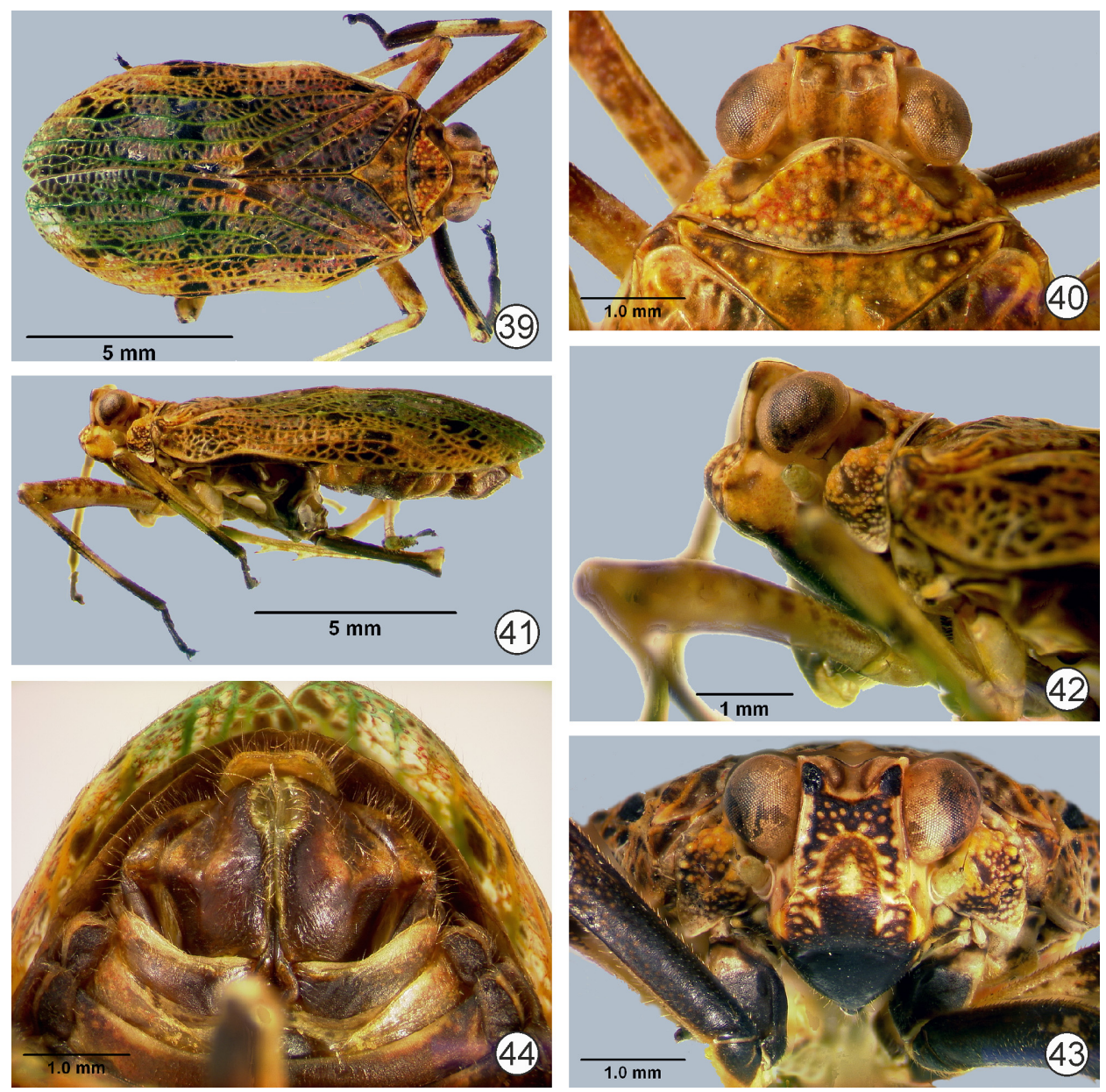

Figs 39-44. Brevicopius gorochovi sp. n., holotype. $39-40=$ dorsal view, $41-42=$ lateral view, $43=$ frontal view, $44=$ ovipositor, ventral view 
et Wang, 2013, both from China. However, Narinosus nativus Gnezdilov et Wilson, 2005 has bilobate hind wings (WANG et al. 2015, fig. 28) and Folifemurum duplicatum Che, Zhang et Wang, 2013 has hind wings rudimentary (CHE et al. 2013, fig. 5). On the other hand according to its trilobate hind wings Nisoprincessa gen. $\mathrm{n}$. is related to the genus Scantinius Stål, 1866 (GNezdiLov 2012, fig. 3) from Borneo (GNezdilov \& Wilson 2007), however, venation is different - Nisoprincessa gen. $n$. almost has not transverse veins, but Scantinius with reticulate venation on main lobes, except anal one. Nisoprincessa gen. $\mathrm{n}$. is very distinctive even within Issidae by the character of fusion of $\mathrm{CuA}$ and $\mathrm{CuP}$ of hind wings which are fused on a long distance medially, but became separated again apically (Fig. 13). In Scantinius as well as in Issini (Thioniina) CuA and CuP are closed or fused apically (GNezDilov 2012, figs 1-2). Also if in Scantinius $\mathrm{Pcu}$ and $\mathrm{A}_{1.1}$ are fused medially on very short distance (almost a point) - in Nisoprincessa gen. $\mathrm{n}$. Pcu and $\mathrm{A}_{1.1}$ are fused medially on rather long distance which is characteristic also for many Oriental Issini (GNezDILOv 2012).

The monotypic genus Thabenula Gnezdilov, Soulier-Perkins et Bourgoin, 2011 described after Fieber's material (GNezDiLov et al. 2011) according to bilobate hind wings and close relationships to the Thabena Stål, 1866 have to be transferred to the tribe Parahiraciini. Thus including the new genus and a new species described above the total number of extant parahiraciine taxa rises to 20 genera with 65 species: Bardunia Stål, 1863 (= Prosonoma Melichar) (8 species), Brevicopius Meng, Qin et Wang, 2015 (2 species), Duriopsilla Fennah, 1956 (1 species), Flavina Stål, 1861 (= Dolia Kirkaldy, = Nilalohita Distant) (10 species), Folifemurum Che, Zhang et Wang, 2013 (1 species), Fortunia Distant, 1909 (= Clipeopsilus Jacobi, 1944 = Parahiracia Ouchi, 1940) (4 species), Fusiissus Zhang et Chen, 2010 (2 species), Mincopius Distant, 1909 (1 species), Narinosus Gnezdilov et Wilson, 2005 (1 species), Neodurium Fennah, 1956 (4 species), Neotetricodes Zhang et Chen, 2012 (5 species), Paratetricodes Zhang et Chen, 2010 (1 species), Pinocchias Gnezdilov et Wilson, 2005 (1 species), Nisoprincessa gen. n. (1 species), Rhombissus Gnezdilov et Hayashi, 2016 (1 species), Scantinius Stål, 1866 (= Dindinga Distant, 1909) (2 species), Tetricodes Fennah, 1956 (4 species), Tetricodissus Wang, Bourgoin et Zhang, 2015 (1 species), Thabena Stål, 1866 ( = Cibyra Stål, = Gelastyra Kirkaldy, = Gelastyrella Yang, = Borbonissus Bonfils, Attié et Reynaud) (14 species), Thabenula Gnezdilov, Soulier-Perkins et Bourgoin, 2011 (1 species).

Acknowledgements - I am glad to thank Dr. Igor Malenovský (Brno, Czech Republic) and Dr. Andrey Gorochov (Saint Petersburg, Russia) for providing the material. The 
study is supported by the Russian Foundation for Basic Research (grant No. 16-04-01143). My work in the National Museum of Wales (Cardiff, UK) was sponsored by the Royal Society (London, UK) and in the Museum für Naturkunde (Berlin, Germany) and Moravian Museum (Brno, Czech Republic) - by the Alexander von Humboldt Stiftung (Bonn, Germany). I am grateful to Dr. Michael R. Wilson (Cardiff, UK), Dr. Igor Malenovský, Dr. Pavel Lauterer (Brno, Czech Republic), and Prof. Dr. Hannelore Hoch (Berlin, Germany) for their hospitality and support.

\section{REFERENCES}

BourgoIn, T. (2017): FLOW (Fulgoromorpha Lists on The Web): a world knowledge base dedicated to Fulgoromorpha. - http://hemiptera-databases.org/flow/

Che, Y., Zhang, Y. \& WANG, Y. (2013): A new genus of the tribe Parahiraciini from China, with notes on the tribe (Hemiptera: Fulgoroidea: Issidae). - Zootaxa 3701(1): 76-82. https://doi.org/10.11646/zootaxa.3701.1.6

Chen, X., Zhang, Z. \& Chang, Z. (2014): Issidae and Caliscelidae (Hemiptera: Fulgoroidea) from China. - Guizhou Science and Technology Publishing House, Guiyang, 242 pp.

Gnezdilov, V. M. (2012): Revision of the tribe Colpopterini Gnezdilov, 2003 (Homoptera, Fulgoroidea, Nogodinidae). - Entomologicheskoe obozrenie 91(4): 757-774 [In Russian; English translation published in Entomological Review (2013), 93(3): 337-353.]

Gnezdilov, V. M. (2013): Modern classification and the distribution of the family Issidae Spinola (Homoptera, Auchenorrhyncha, Fulgoroidea). Entomologicheskoe obozrenie 92(4): 724-738 [In Russian; English translation published in Entomological Review, 2014, 94(5): 687-697.] https://doi.org/10.1134/S0013873814050054

Gnezdilov, V. M. (2015): First coloured species of the genus Thabena Stal (Hemiptera, Fulgoroidea, Issidae) from Vietnam with general notes on the genus. - Acta Zoologica Academiae Scientiarum Hungaricae 61(4): 329-339. https://doi.org/10.17109/ AZH.61.4.329.2015

Gnezdilov, V. M. \& Bourgoin, T. (2016): On the taxonomic position of Issus reticulatus Bervoets, 1910 (Hemiptera: Fulgoroidea: Issidae) from Baltic amber. - Entomological Review 96(5): 631-633. https://doi.org/10.1134/S0013873816050092

Gnezdilov, V. M. \& Hayashi, M. (2016): New genus of the family Issidae (Hemiptera: Fulgoroidea) from Japan. - Japanese Journal of Systematic Entomology 22(1): 47-49.

Gnezdilov, V. M., Holzinger, W. E. \& Wilson, M. R. (2014): The Western Palaearctic Issidae (Hemiptera, Fulgoroidea): an illustrated checklist and key to genera and subgenera. - Proceedings of the Zoological Institute RAS, Vol. 318, Supplement 1, 124 pp.

Gnezdilov, V. M., Soulier-Perkins, A. \& Bourgoin, T. (2011): Fieber's original drawings and their corresponding types for the family Issidae (Hemiptera, Fulgoromorpha) in the Muséum national d'Histoire naturelle of Paris, France. - Zootaxa 2806: 24-34.

Gnezdilov, V. M. \& Wilson, M. R. (2007): Review of the genus Scantinius Stål with notes on the tribe Parahiraciini Cheng \& Yang (Hemiptera: Auchenorrhyncha: Fulgoroidea: Issidae). - Arthropod Systematics \& Phylogeny 65(1): 101-108.

Meng, R., Qin, D. \& Wang, Y. (2015): A new genus of the tribe Parahiraciini (Hemiptera: Fulgoromorpha: Issidae) from Hainan Island. - Zootaxa 3956(4): 579-588. https://doi. org/10.11646/zootaxa.3956.4.9 
WAng, M., Bourgoin, T. \& Zhang, Y. (2015): A new genus of the tribe Parahiraciini from Southern China (Hemiptera: Fulgoroidea: Issidae). - Zootaxa 3957(1): 77-84. https:// doi.org/10.11646/zootaxa.3957.1.6

Zhang, Z. \& Chen, X. (2013): Taxonomic study on the tribe Parahiraciini (Fulgoromorpha: Issidae). - Journal of Jinggangshan University (Natural Science) 34(1): 101-106.

Received August 3, 2016, accepted January 15, 2017, published October 20, 2017 